\title{
Evaluation instrument of nutrition literacy on adults (EINLA) A validity and reliability study
}

\author{
Cesur B ${ }^{1 *}$, Koçoğlu $\mathrm{G}^{2}$ and Sümer $\mathrm{H}^{2}$ \\ ${ }^{1}$ Cumhuriyet University, Faculty of Health Sciences, Midwifery Department, Sivas, Turkey \\ ${ }^{2}$ Cumhuriyet University, School of Medicine, Public Health Department, Sivas, Turkey
}

\begin{abstract}
Introduction: Literacy has a key role in eating habits. With the integration of nutrition science and literacy, and with the establishment of nutrition literacy vision in society, people can be helped to increase their control over their eating behaviors and to lead a more healthy way of life.

Objective: This study was conducted to develop a valid and reliable nutrition literacy assessment tool.

Materials and methods: The Evaluation Instrument of Nutrition Literacy on Adults developed to assess the development of Nutrition Literacy was applied to 266 people residing in Sivas, a province in Turkey. The participants were at least elementary school graduates and between the age of 18 and 64 . Experts' opinions regarding the assessment tool were found to be consistent with each other. Upon the completion of factor analysis conducted to assess construct validity, all but one of the items (item 1) in the assessment tool were determined to have load factors greater than 0.30 and the tool considered to have a 5 -factor structure. In order to investigate the reliability of the responses given to questions, the assessment tool was reapplied to 60 people selected by systematic sampling methods three weeks after its first administration, and the correlation coefficient was found to be 0.85 using the test-retest method. The Cronbach's alpha reliability coefficient of the assessment tool was 0.75 . The mean item difficulty and discriminant indices were 0.552 and 0.730 respectively. After the validity and reliability analysis, of the 38 items in the assessment tool, three were removed, thus, the Evaluation Instrument of Nutrition Literacy on Adults consisted of 35 questions.
\end{abstract}

Conclusion: The analysis revealed that the "Evaluation Instrument of Nutrition Literacy on Adults" is a valid and reliable tool and can be used to assess nutrition literacy.

\section{Introduction}

Although the term "nutrition practices" is generally preferred in the nutrition-related literature, today the term "literacy practices" is mentioned since it includes individuals' active participation [1]. Nutrition literacy is defined as an individual's ability to access, understand, interpret and apply nutrition-related basic information and services to promote and maintain good health [2-4]. Nutrition literacy requires a high level of complex cognitive skills, since it requires skills related to principles of nutrition and food [4-6].

In studies conducted on the health literacy and nutrition literacy, nutrition literacy skills were determined to be associated with nutrition skills such as the size of servings, the meaning of food labels, access to reliable sources of information about nutrition, and acquaintance with the basic nutrition information [4,5]. Current health literacy assessment tools cannot evaluate the nutrition literacy [4-6]. Although several studies have been performed on health literacy during the last few years In Turkey, there are no measurement tools with established reliability and validity used to determine the nutritional literacy levels. In this study, a measurement tool to assess nutrition literacy among people in Turkey was developed by conducting a detailed literature review and evaluating health and nutrition literacy assessment instruments used in the world.

\section{Population and sample of the study}

When the validity and reliability study of a scale is conducted, it is recommended that the sample should include 5-10 people for each item [7]. The number of the items in the Nutrition Literacy Assessment Tool developed in this study was 38 . Therefore, the study was continued until the number of the 18-64-year-old participants living in Sivas reached $266(38 \times 7)$. To calculate how many people from each of 63 neighborhoods in Sivas would be included in the study, the researchers utilized Çınar (1994) and Selvi's (2008) study and used the proportional selection method [8,9]. Of the households living in houses/apartments chosen through the simple random sampling method, those who met the study criteria and agreed to participate in the study were included in the study [9]. After the participants were informed of the study and their informed consents were obtained, the questionnaire was administered through face-to-face interviews. The participants were asked to carefully read each item and then to answer it. The study comprised people who resided in the province of Sivas and agreed to participate in the study. The participants were at least elementary school graduates and between the age of 18 and 64 .

\section{Data collection tools}

The Personal Information Form and Evaluation Instrument of Nutrition Literacy on Adults were used as data collection tools.

Correspondence to: Cesur B, Cumhuriyet University, Faculty of Health Sciences, Midwifery Department, Sivas, Turkey, E-mail: bbusracak@gmail.com

Key words: literacy, nutrition literacy, instrument of nutrition literacy

Received: December 20, 2014; Accepted: January 14, 2015; Published: January 18,2015 


\section{Analysis of the data}

The data were coded and analyzed using the SPSS 14.0 (Statistical Program for Social Sciences). To establish the content and construct validity of the Evaluation Instrument of Nutrition Literacy on Adults, the Cronbach's alpha reliability coefficient and the test-retest method were used. The item difficulty degree $(\mathrm{p})$ and item discrimination power $(r)$ were calculated using the Iteman analysis program (3.50).

\section{Ethical aspects of the study}

To conduct the study, approval of the Cumhuriyet University Clinical Research Ethics Committee and the permission of the Governor of Sivas were obtained. Then, the participants were informed of the study and their informed consents were obtained.

\section{Evaluation instrument of nutrition literacy on adults (EINLA) a validity and reliability study}

In order to determine the discrimination level of each item in the Evaluation Instrument of Nutrition Literacy on Adults and their conformity to cultural norms, content validity was conducted $[10,11]$. The preform of the "Evaluation Instrument of Nutrition Literacy on Adults" prepared for this purpose was sent to 10 experts. The experts were requested to score each item from 1 to 4 ( $1=$ 'completely inappropriate', 2='not appropriate', 3='appropriate', 4='completely appropriate') while assessing the appropriateness of the items in the assessment tool [11]. The mean and standard deviation values given by the experts to the scale sent to them to assess its content validity are given in Table 1.

As is seen in Table 1, the mean values for the responses given by the experts to assess their suitability for content validity were high. Based on the experts' scoring, it can be said that item 6 was the most appropriate one $(\mathrm{X}=3.90, \mathrm{SD}=.32)$ and item 36 was the least appropriate one $(\mathrm{X}=2.90, \mathrm{SD}=.74)$. Compliance level of expert opinions was analyzed with Kendall $\mathrm{W}$ analysis, a non-parametric test [12]. Administration of a questionnaire to $10-20$ people with similar characteristics but not

Table 1. The mean and standard deviation values given to each item on the "Nutrition Literacy Assessment Tool for Adults" by the experts to assess content validity.

\begin{tabular}{|c|c|c|c|c|c|}
\hline Item Number & $\mathbf{X}$ & $\mathbf{S s}$ & Item Number & $\mathbf{X}$ & $\mathbf{S s}$ \\
\hline Item 1 & 3.30 & .67 & Item 20 & 3.30 & .82 \\
\hline Item 2 & 3.60 & .52 & Item 21 & 3.60 & .52 \\
\hline Item 3 & 3.50 & .71 & Item 22 & 3.60 & .52 \\
\hline Item 4 & 3.70 & .48 & Item 23 & 3.60 & .52 \\
\hline Item 5 & 3.50 & .71 & Item 24 & 3.70 & .48 \\
\hline Item 6 & 3.90 & .32 & Item 25 & 3.30 & .82 \\
\hline Item 7 & 3.20 & .79 & Item 26 & 3.50 & .53 \\
\hline Item 8 & 3.40 & .70 & Item 27 & 3.50 & .53 \\
\hline Item 9 & 3.60 & .70 & Item 28 & 3.30 & .67 \\
\hline Item 10 & 3.70 & .67 & Item 29 & 3.30 & .67 \\
\hline Item 11 & 3.50 & .71 & Item 30 & 3.50 & .53 \\
\hline Item 12 & 3.30 & .95 & Item 31 & 3.10 & .57 \\
\hline Item 13 & 3.00 & .94 & Item 32 & 3.60 & .52 \\
\hline Item 14 & 3.20 & .92 & Item 33 & 3.50 & .53 \\
\hline Item 15 & 3.30 & .82 & Item 34 & 3.40 & .84 \\
\hline Item 16 & 3.60 & .84 & Item 35 & 3.00 & .67 \\
\hline Item 17 & 3.50 & .71 & Item 36 & 2.90 & .74 \\
\hline Item 18 & 3.50 & .53 & Item 37 & 3.20 & .42 \\
\hline Item 19 & 3.30 & .82 & Item 38 & 3.60 & .52 \\
\hline & & & & & \\
\hline
\end{tabular}

included in the sample and getting their opinions on whether the items are comprehensible, eliminating the shortcomings and errors of the questionnaire and then giving the final form to it are an important step in the development of the items [13].

After the expert assessments and compliance analysis, some of the items were revised. Then the tool was administered to 10 people with characteristics similar to those of the participants in the sample. The items misunderstood were revised, and the assessment tool took its final form. Prior to the factor analysis to be performed to determine the assessment tool's construct validity, the Kaiser-Meyer-Olkin (KMO) analysis was conducted to determine the sampling adequacy and Bartlett's Test of Sphericity was carried out to determine the sample size. In order to establish the appropriateness of factor analysis, the score obtained from the KMO analysis should be higher than 0.60 , and the result of Bartlett's Test of Sphericity should be statistically significant $[9,14]$.

After the analysis of the assessment tool, the KMO value was determined as 0.76 and Batlett's test of Sphericity was determined to be significant $(\mathrm{p}<0.05)$. These results indicate that the assessment tool was suitable to undergo factor analysis

During the factor analysis, in order to identify sub-factors in the assessment tool independently of each other, the Varimax orthogonal rotation method was preferred. After this rotation, the Evaluation Instrument of Nutrition Literacy on Adults was found to have a fivefactor structure. To determine the number of factors in the assessment tool, Eigen values and Scree plots were used. During the analysis, all but one of the items (item 1) in the assessment tool were determined to have load factors greater than 0.30

During the factor analysis, it was determined that the $1^{\text {st }}$ factor of the Evaluation Instrument of Nutrition Literacy on Adults accounted for $13.3 \%$ of the total variance, the $2^{\text {nd }}$ factor $21.4 \%$ of the total variance, the $3^{\text {rd }}$ factor of $26.8 \%$ of the total variance, the $4^{\text {th }}$ factor $32.0 \%$ of the total variance and the $5^{\text {th }}$ factor $36.1 \%$ of the total variance factor. Upon the completion of the factor analysis, the load factor of the $1^{\text {st }}$ item was determined as 0.15 and thus it was removed from the assessment tool.

\section{Reliability study of the evaluation instrument of nutrition literacy on adults}

In order to investigate the reliability of the responses given to questions, the assessment tool was reapplied to 60 people selected by systematic sampling methods three weeks after its first administration, and the correlation coefficient was found to be 0.85 using the test-retest method. In knowledge tests, the reliability of the assessment tool can be estimated using the Kuder-Richardson Formula 20 (KR 20) and KuderRichardson Formula 21 (KR 21). If the assessment tool is a knowledge test and contains only one correct answer, correct answers are coded as 1 and wrong answers as 0 . When the items have two categories ( 0 and 1) Alpha Coefficient and KR-20 give the same result. In other words, KR-20 is a special case of Cronbach's alpha coefficient, and if the items have two options coded as $0-1$, reliability can be calculated with the Cronbach's alpha coefficient [15]. The Cronbach's alpha reliability coefficient for the Evaluation Instrument of Nutrition Literacy on Adults was calculated as 0.75 .

The item difficulty degree (p) and item discrimination power (r) were calculated using the Iteman analysis program (3.50). As a result of the item analysis, the mean item difficulty and discriminant indices of the assessment tool were found to be 0.552 and 0.730 respectively. According to the results of this analysis, item difficulty and discriminant 
indices were considered acceptable. These results indicate that the "Evaluation Instrument of Nutrition Literacy on Adults" is a valid and reliable tool.

Some statistical data related to the item analysis of "Evaluation Instrument of Nutrition Literacy on Adults" are given in Table 2.

With the validity study, item difficulty degrees ( $\mathrm{p}$ ) and item discrimination powers $(r)$ were calculated. When the item discrimination power $(r)$ which indicates how well an item distinguished low scores from high scores was examined, the items with a discrimination index higher than 0.40 were considered to have a high discrimination power, the items with a discrimination index between 0.30 and 0.39 were considered to have quite a high discrimination power, the items with a discrimination index between 0.20 and 0.29 were considered to have a poor discrimination power, and the items with a discrimination index lower than 0.19 were considered to have a low discrimination power. When the item difficulty values (p) calculated based on the responses given by the participants were examined, the items with a difficulty index lower than 0.29 were considered very difficult, the items with a difficulty index between 0.30 and 0.49 were considered moderately difficult, the items with a difficulty index between 0.50 and 0.69 were considered easy and the items with a difficulty index between 0.70 and 1.00 , were considered very easy $[10,11]$. The discrimination power $(r)$ and difficulty degree (p) of each item are given in Table 3 .

As is seen in Table 3, item 1 was considered poor because its discrimination power was 0.29 , and items 21 and 22 were considered low because their discrimination power was 0.13 . Given the item difficulty values, items 30 and 31 were considered difficult because their difficulty values were lower than 0.29 . Therefore, items 1,30 and 31 were removed from the tool because item 1 had very low discrimination power and items 30 and 31 had a very low difficulty level. Although their discrimination power was low, items 21 and 22 were not removed from the instrument, because if they had been removed from the insrument, foods belonging to meat, egg and legume groups would have had to be removed too because of the four-leaf clover pattern, which was considered inappropriate.

As a result, the "Evaluation Instrument of Nutrition Literacy on Adults" which had 38 items at the beginning was composed of 35 items, because 3 items were removed from the instrument.

\section{Conclusion}

Upon the completion of the validity and reliability study of the assessment tool developed by the researcher to determine the nutrition literacy status by reviewing the literature, three items were removed from the tool. The tool comprised five sections. The possible maximum

Table 2. Some statistical data related to the item analysis of "Evaluation Instrument of Nutrition Literacy on Adults".

\begin{tabular}{|l|l|}
\hline \multicolumn{2}{|c|}{ Data Related to the Assessment Tool } \\
\hline The number of the items & 38 \\
\hline The number of the participants & 266 \\
\hline Mean & 26.014 \\
\hline Standard Devision & 7.591 \\
\hline Cronbach Alpha & 0.75 \\
\hline Skewness & 0.249 \\
\hline Kurtusis & -0.347 \\
\hline Mean item difficulty & 0.522 \\
\hline Mean item discrimination & 0.730 \\
\hline
\end{tabular}

Table 3. Item discrimination powers (r) and item difficulty degrees ( $\mathrm{p}$ ) of the "Evaluation Instrument of Nutrition Literacy on Adults".

\begin{tabular}{|c|c|c|c|c|c|}
\hline Item Number & $\mathbf{r}$ & $\mathbf{p}$ & Item Number & $\mathbf{r}$ & $\mathbf{p}$ \\
\hline Item 1 & .29 & .36 & Item 20 & .70 & .86 \\
\hline Item 2 & .36 & .76 & Item 21 & .13 & .93 \\
\hline Item 3 & .43 & .76 & Item 22 & .13 & .92 \\
\hline Item 4 & .49 & .53 & Item 23 & .78 & .95 \\
\hline Item 5 & .40 & .72 & Item 24 & .77 & .94 \\
\hline Item 6 & .51 & .83 & Item 25 & .63 & .82 \\
\hline Item 7 & .38 & .68 & Item 26 & .68 & .94 \\
\hline Item 8 & .60 & .75 & Item 27 & .50 & .55 \\
\hline Item 9 & .43 & .86 & Item 28 & .61 & .35 \\
\hline Item 10 & .52 & .65 & Item 29 & .63 & .32 \\
\hline Item 11 & .32 & .48 & Item 30 & .32 & .03 \\
\hline Item 12 & .66 & .77 & Item 31 & .37 & .09 \\
\hline Item 13 & .34 & .91 & Item 32 & .47 & .73 \\
\hline Item 14 & .45 & .86 & Item 33 & .43 & .64 \\
\hline Item 15 & .55 & .80 & Item 34 & .31 & .90 \\
\hline Item 16 & .56 & .79 & Item 35 & .57 & .44 \\
\hline Item 17 & .61 & .58 & Item 36 & .57 & .33 \\
\hline Item 18 & .72 & .95 & Item 37 & .49 & .73 \\
\hline Item 19 & .73 & .91 & Item 38 & .52 & .56 \\
\hline & & & & & \\
\hline
\end{tabular}

score to be obtained from the tool was determined as $35[2,4,5,6,14]$.

The first section included items on general nutrition information, the second section on reading comprehension and interpretation, the third section on food groups, the fourth section on the serving sizes, and the fifth section on how to read food labels and ability to do simple calculations. While each correct answer was given one point, unanswered or incorrectly answered items were given 0 points. When nutrition literacy level was graded, a total score between 0 and 11 was considered as insufficient, between 12 and 23 as borderline and between 24 and 35 as sufficient. In line with the results of the analysis, the "Evaluation Instrument of Nutrition Literacy on Adults" can be said to be a valid and reliable intrument.

PC: This instrument has been developed within the scope of a doctoral dissertation

\section{Acknowledgement}

This study was supported by Cumhuriyet University Scientific Research Unit.

\section{References}

1. Cimbaro MA (2008) Nutrition literacy: Towards a new conception for home economics education, The University of British Columbia, Vancouver.

2. Zoellner J, Connell C, Bounds W, Crook L, Yadrick K (2009) Nutrition literacy status and preferred nutrition communication channels among adults in the Lower Mississippi Delta, Centers for Disease Control and Prevention, 6: 1-11.

3. Diamond JJ (2007) Development of a reliable and construct valid measure of nutritional literacy in adults. Nutr $J 6: 5$. [Crossref]

4. Carbone ET, Zoellner JM (2012) Nutrition and health literacy: a systematic review to inform nutrition research and practice. J Acad Nutr Diet 112: 254-265. [Crossref]

5. Gibbs H, Chapman-Novakofski K (2012) Exploring nutrition literacy: Attention to assessment and the skills clients need, Health, 4: 120-124.

6. Carbone ET (2013) Measuring nutrition literacy: Problems and potential solutions. $J$ Nutr Disorders Ther 3: 1.

7. Pallant J (2005) SPSS survival manual: A step by step guide to data analysis using SPSS for Windows. (2nd Edn.), Sabon By Bookhouse, Sydney. 
8. Çınar Z, Sümbüloğlu K, Alpar R (1994) The development of varied numbers and quality of sampling plans for the purpose of using them in the field studies that will do in Sivas. Cumhuriyet Medical Journal 16: 191-196.

9. Selvi P (2008) The development of varied numbers and quality of sampling plans for the purpose of using them in the field studies that will do in Sivas Cumhuriyet University, Health Sciences Institute, Department of Biostatistics, Master Thesis, Sivas.

10. Aydemir Ö, Köroğlu E (2009) Clinical scales used in psychiatry HYB Printed Publication, Ankara, Turkey: 440-449.

11. Aker S, Dündar C, Pekşen Y (2005) Two vitaly consept of measurement instruments: Validity and reliability. Journal of Experimental and Clinical Medicine 22: 50-60.

12. Gözüm S, Aksayan S (2003) A guide for transcultural adaptation of the scale 11: psychometric characteristics and cross-cultural comparison. Journal of Research and Development in Nursing 1: 3-14.

13. Bowling A and Ebrahim S (2005) Handbook of health research methods: Investigation, measurement and analysis, Open University Press. Bell and Bain Ltd, Glasgow.

14. Akın Ü, Akın A, ve Abacı R (2007) Self-Compassion Scale: The study of validity and reliability, H U Journal of Education 33: 1-10.

15. Alpar R (2010) Sports, Health and applied statistics and reliability and validity with examples of educational science, Detay Publishing, Ankara.

16. Pettersen S, Kjøllesdal JG, Aarnes SB (2009) Measuring nutrition literacy, Paper presented at the 19th International Conference of Nutrition, Bangkok, Thailand.

Copyright: $@$ 2015 Cesur B. This is an open-access article distributed under the terms of the Creative Commons Attribution License, which permits unrestricted use, distribution, and reproduction in any medium, provided the original author and source are credited. 